\title{
Towards the Workflow-enabled Civil Construction Enterprise Integration
}

\author{
Mário Paulo Teixeira Pinto(a), João José Pinto Ferreira(b) \\ (a) Superior School of Industrial Studies and Management. Polytechnic Institute of Porto \\ Av. Mouzinho de Albuquerque, 324490 - 409 Povoa de Varzim - Portugal \\ email:mariopinto@eseig.ipp.pt \\ (b) Engineering Faculty of Porto University / Electrical Engineering \& Computers Dpt. \\ INESC Porto - Manufacturing Systems Engineering Unit \\ Rua José Falcão , 110, 4050 - 315, Portugal \\ email: jjpf@fe.up.pt, URL: http://www.fe.up.pt/ jjpf
}

\begin{abstract}
This paper presents the result of a research project. In the course of this project we demonstrated the application of business process management concepts in the extended construction enterprise, by using a Workflow Management System. The civil construction enterprise presents, usually, a distributed organisational structure (strategic enterprise, construction sites, warehouses, head-offices, etc.), and operates in a transient and variable environment, according to the collection of works in progress. A common scenario is the construction process that involves the co-ordination of many smaller firms (subcontractors), normally coordinated by one contractor. In this context, the paper starts with the presentation of the civil construction enterprise, by briefly describing the organisational, functional and process models, and concentrates its discussion in the supply chain business process. The rationale for this process is further presented based on so-called construction enterprise basic building block, capable of being replicated for each construction entity. Follows the presentation of a prototype illustrating the above concepts and demonstrating the value added of such approach. Workflow technology will definitely become the cornerstone technology to support B2B E-Business scenarios in areas such as Construction. In this paper we will further discuss this topic by bringing new construction enterprise requirements in the event of such as the usage of new mobile terminals such as UMTS, PDAs, and so on.
\end{abstract}




\section{THE CIVIL CONSTRUCTION ENTERPRISE}

The construction enterprise presents, usually, a distributed organisational structure (strategic enterprise, construction sites, warehouses, head-offices, etc.), and operates in a transient and variable environment, comprising the concurrent management of far apart construction sites. Construction industry uses a very unstable and transient workforce. The result of a construction project is usually a custom-built product from numerous raw materials and components, drawn from several sources. Unlike advanced manufacturing industries, concepts such as controlled working conditions, parallel working, standardisation, and innovation, are not embedded in the construction industry.

Another familiar scenario to civil construction is widespread usage of subcontracting, transferring to these enterprises the responsibility to execute some specific construction activities. To this end, the construction process typically involves the co-ordination of many smaller firms (subcontractors) controlled and monitored by the contractor. The effective co-ordination and communication of these smaller firms by the principal contractor is essential to the success of any project. This clearly demands the usage of adequate decentralised business process co-ordination infrastructures, allowing firms to contribute to common process integration [7].

Basic functions and interactions in the civil construction enterprise are illustrated in figure 1 (derived from [8]). The information, material, management and financial flows are also illustrated. This description further includes all the extended enterprise participants (main contractor, subcontractors and suppliers) and locations (construction sites, warehouses and had offices).

A construction enterprise is, typically, structured in the following organisational areas:

- Management enterprise, including the strategic planning and the administrative area;

- Technologic planning, with activities related by engineering like I\&D, projects, works budgeting;

- Works planning, responsible to determine the needs of materials, workmanship and equipments, supported in MRP ("material requirements planning) and CRP (Capability requirements planning); Works control, in three aspects:

- costs, chronogram and quality standards; Construction sites, with the production development, material and quality control, and measurement of works realised;

- Equipments parks (and head-offices), responsible to management and maintenance of machines; 
- Warehouses, responsible to material management, and so to the materials flows to the construction sites.

These organisational areas are responsible for the execution of an extensive number of business functions [5]. These functions (and organisational areas) are in fact replicated in several nodes of the extended enterprise. As examples we would highlight examples such as construction sites, equipments parks and warehouses. The number and location of these functional units is in fact variable in time, and depends on the actual work in progress.

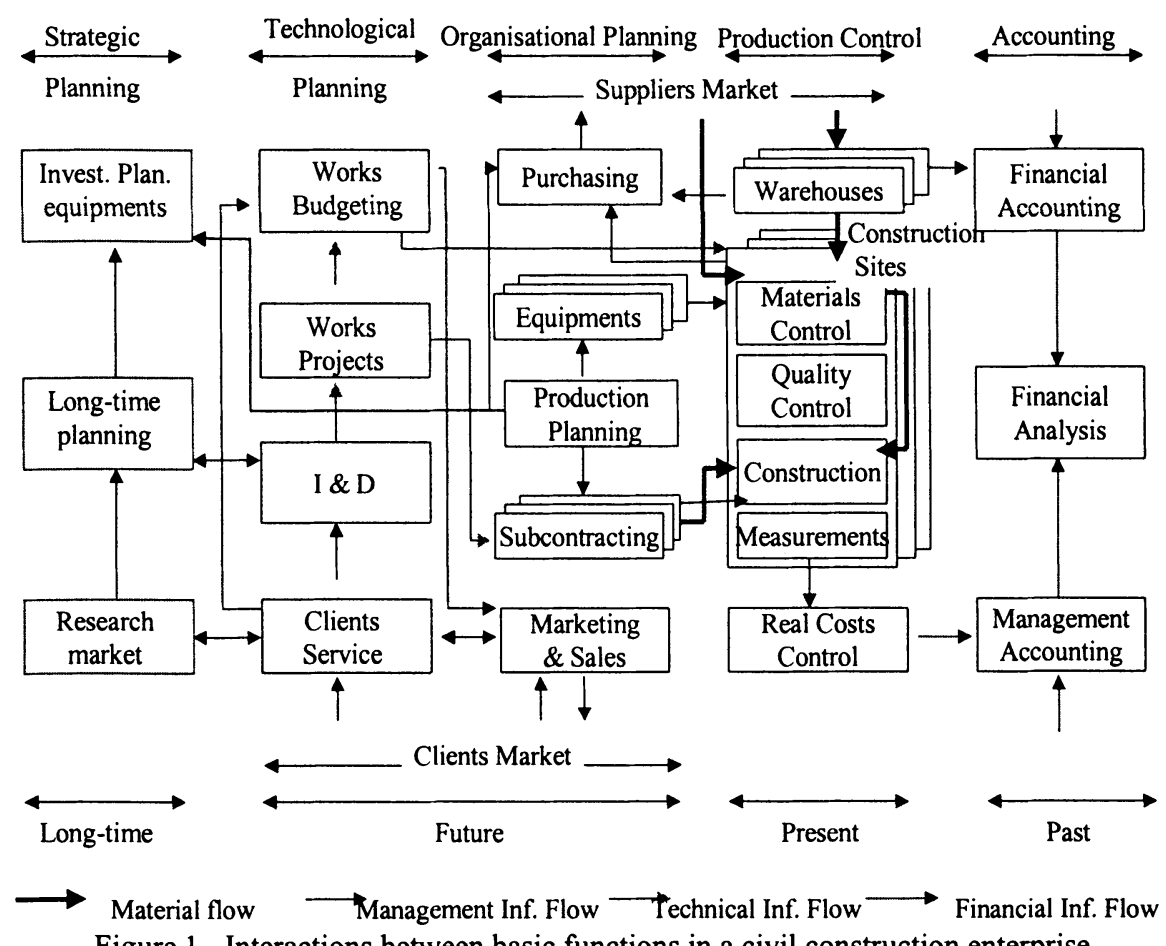

Figure 1 - Interactions between basic functions in a civil construction enterprise

\section{THE CIVIL CONSTRUCTION SUPPLY CHAIN}

\subsection{The Supply Chain (SC) building block}

A common scenario is the construction process that involves the coordination of many smaller firms (subcontractors), normally coordinated by one contractor. From this perspective, and by analysing the construction company supply-chain, the extended construction company building block was derived (figure 2). This basic construct is therefore replicated for each contractor and sub-contractor recursively. 
The Extended Construction Company

The Basic Building Block

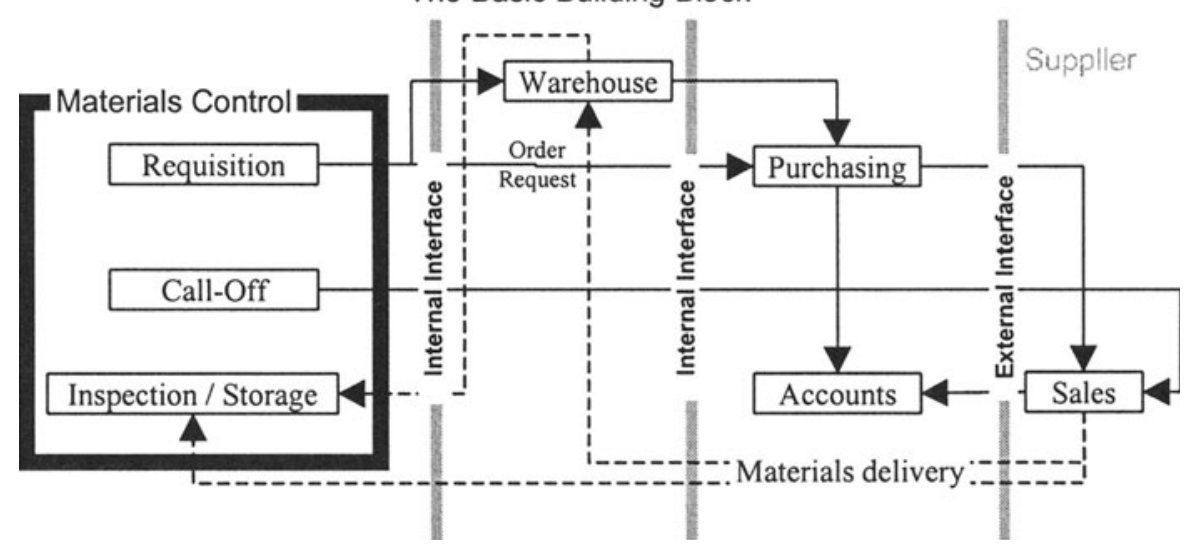

Figure 2 - The Extended construction company building block [3]

For each construction entity, we identified four distinct environments, with interfaces enabling the communication among them: construction site, warehouse, administrative area and suppliers. The materials control, in the construction site, allows the local materials management. At the warehouse, materials management is performed for several construction sites according to their respective production plans. The warehouse is also an intermediary between the construction sites (getting materials requisitions) and the purchasing area (release purchasing orders). The administrative area is responsible for accounting and for processing purchasing orders. Suppliers deliver materials to the construction entity, either at the warehouse or at the actual construction site. We can analyse with more details some one of these functionalities described in figure 2:

- Inspection/Storage is a functionality that provides the materials quality control.

- Call-off enables a contact with supplier to ask for the next shipment for a previously negotiated (for this type of orders, we have for example agreed phased deliveries at the construction site, allowing a lower local material stocks).

- Requisition is an order request that is sent from construction site to the warehouse or purchasing area

- Warehouse The global materials management is performed at the warehouse. Products are received from suppliers and delivered at construction sites.

- Purchasing is the department responsible for receiving material requests from construction site or/and warehouse, and for producing 
purchasing orders to suppliers. It also makes deals and agreements with suppliers (namely procurement), to get the best conditions.

- Accounts processes the financial and management accounting information.

- The Sales department is part of any supplier. Receives purchasing orders and provide the materials delivered ether at the warehouse or at construction site according the established contract.

\subsection{Interoperability across SC members}

The relationships between contractors and sub-contractors were further identified as being contract based. This interaction, as illustrated in figure 3, features a complex and dynamic relationship [3]:

- The need for the contract emerges from the actual production plan

- Contract manager handles the detailed contract elaboration and starts the process

- From the actual moment when the sub-contractor starts its own activity, the contractor starts the regular monitoring of the work in progress. This monitoring activity is a corner stone to feeding back information both for accounting and for construction management.

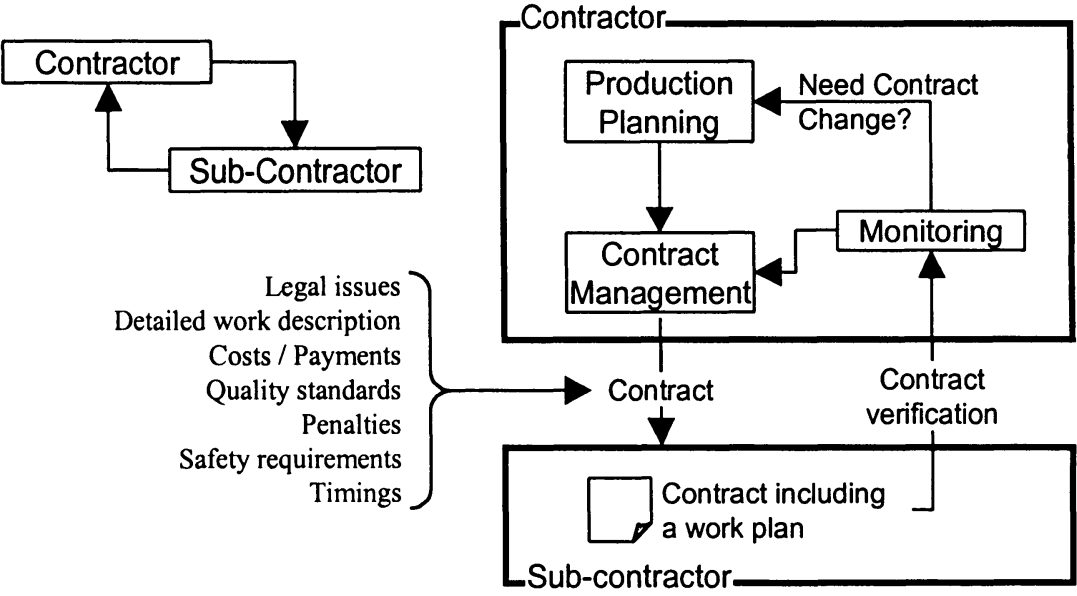

Figure 3 - The contract-based relationship

The relationship between contractor and sub-contractor works in both directions, and demands coordination and interoperability between processes. Inside a hierarchic level, the sub-contractor could be analysed like a contractor, establishing and executing a work plan. He will have to perform its own resource management and, if necessary, manage its sub-contractors. 


\section{WORKFLOW SUPPORT}

\subsection{Rationale}

The approach to enterprise integration rests in the usage of a workflow backbone to support interoperability and integration with legacy systems, and the construction of a scalable and networked solution. On the other hand, the aim is to provide tools for the management of change by building on business process model-based co-ordination solutions to support daily construction management operations.

The inherent geographical distribution and number of acting entities (namely the contractor and sub-contractors as well as the other participants in the supply chain), clearly demands the usage of stage-of-the-art workflow management tools and the need of interoperability [1]. Moreover, only a distributed infrastructure supporting the so-called extended construction organization will enable innovative communication and collaboration across the networked organization. The rationale for the authors approach is further illustrated in figure 4, picturing the WFMS (Workflow Management System)-based business process model enactment [3].

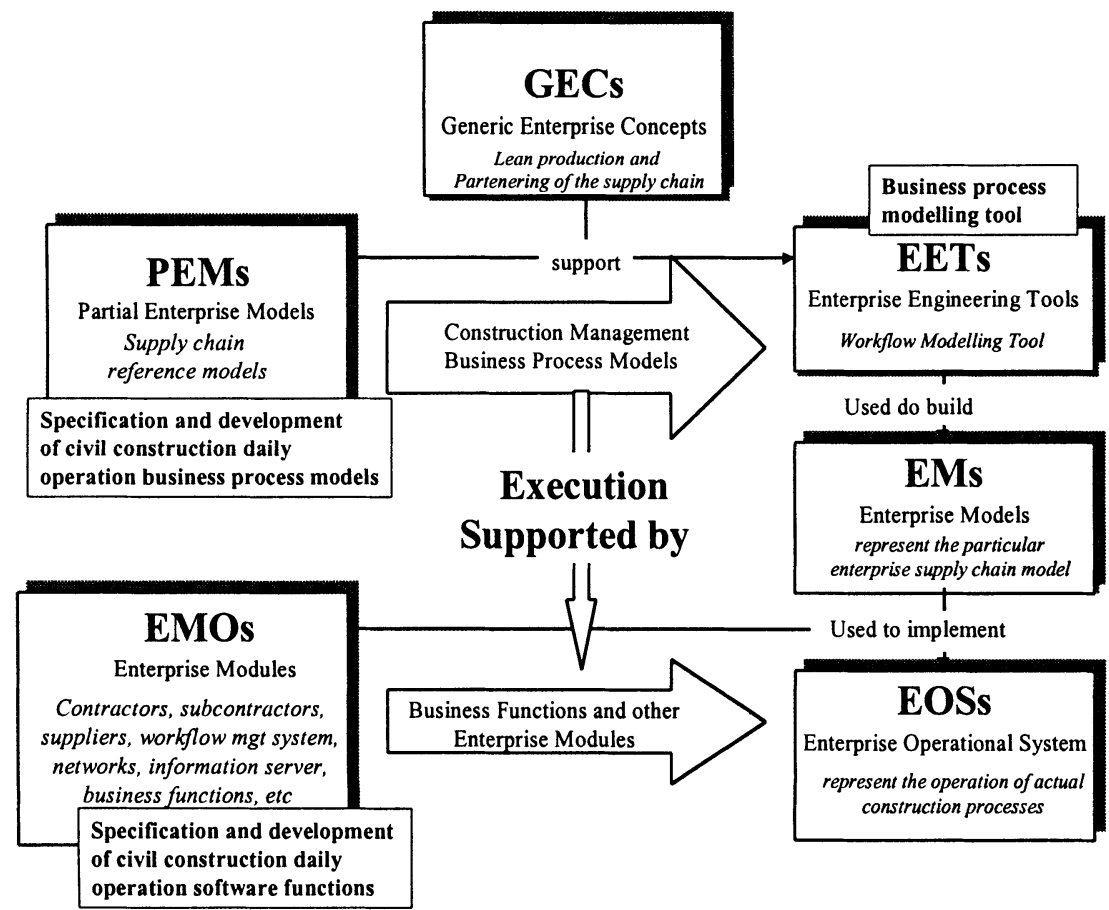

Figure 4 - Enterprise Integration Approach [4] 
In this scenario, a distributed workflow management environment is responsible for enabling co-operation and inter-operation of business processes across enterprise boundaries in the construction extended enterprise.

\subsection{Case Study}

The distributed model execution of business processes are based on the so-called Move and Produce primitives derived from the Activity Production Control Architecture [2]. These primitives enable business process execution by describing process activities and the corresponding functional entity responsible for its execution, be it a software module, machine or human resource. The Move primitive supports information or material flows, and the Produce primitive supports the actual task performance. Execution primitives support therefore the interchange of orders and status reporting between the workflow engine and the functional entity performing the actual operations.

The supply chain model process execution is based the execution of successive Move and Produce activities, according a particular production plan. In this scenario, the entity responsible to execute one activity, receives jointly instructions and information necessary to start the activity. Upon its conclusion, the involved entity will make available the resulting product, namely to the following entity.

Figure 5 illustrates the requisition of materials (in the construction site) and the processing of a purchasing order (in the warehouse). The Produce primitive enables the form filling for material requisition comprising information such as the product type, quantity and delivery deadline. The Move primitive then supports the material requisition transfer from construction site to the warehouse. The following activity, performed in the warehouse, receives information (filled requisition form) and if necessary prepares a purchasing order to fulfil the received material request. 


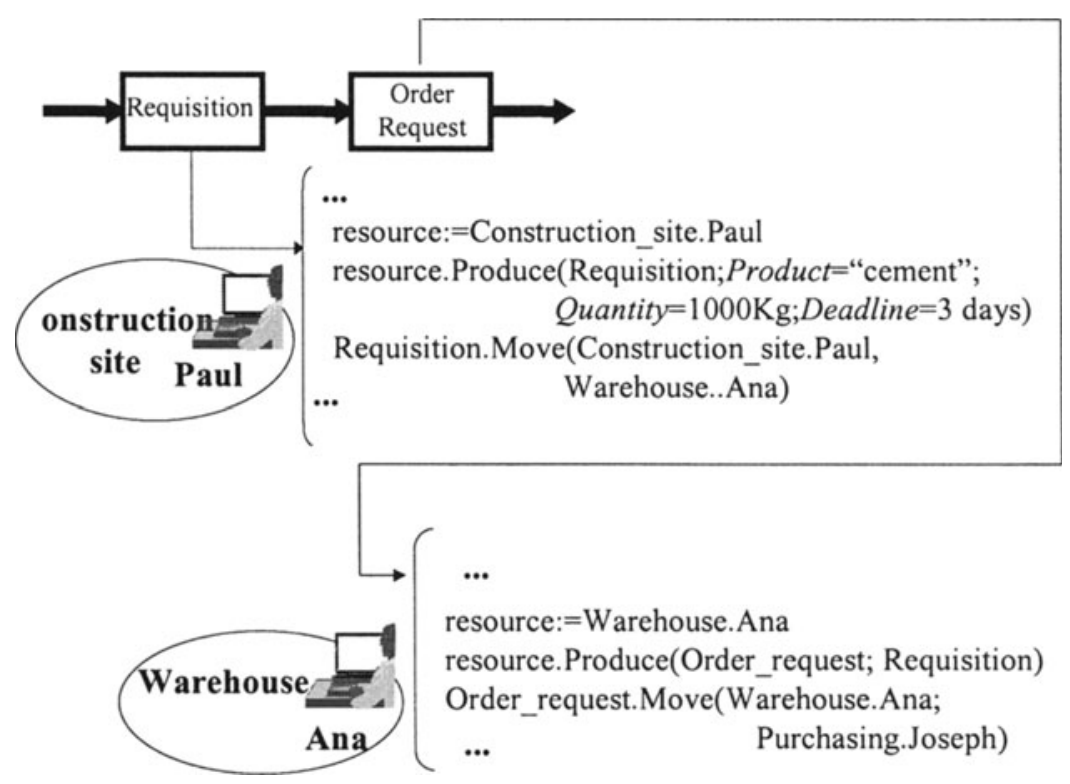

Figure 5 - Supply chain conceptual model

\section{CONCLUSIONS}

Unlike in advanced manufacturing industries, the concepts of controlled working conditions, parallel working, standardisation and innovation, are not truly embedded in the construction industry. It is, therefore a most interesting green field to bring in new electronic business concepts. The challenge in this area derives from the multiple existing physical and organisational boundaries of such company. Supply chain management in the construction industry seems to be a critical area to driving innovation and to sustaining incremental and continuous improvement. Effective implementation of supply chain integration leads to performance improvement in the shape of reduced costs and better quality.

Workflow technology could become a key to support business process integration in areas such as construction, providing management tools and interoperability between processes. It offers modelling tools and supports coordination in a distributed environment. To this environment, we would bring in new requirements in a construction enterprise to improve a communication and collaboration across the networked organisation. Particular attention should be given to the convergence of wireless networks and INTERNET. In such a transient and variable environment new roles will for sure be given to $3^{\text {rd }}$ Generation mobile terminals in the construction environment. 


\section{References}

1. [Aalst]

"Interorganizational Workflows". Department of Mathematics and Computing Science, Eindhoven University of Technology

2. [Bauer]

Bauer et. Al; "Shop Control Systems: From Design to Implementation"; Chapman \& Hall; ISBN 0-412-36040-3;

3. [Ferreira]

João José Pinto Ferreira, David Proverbs, Manuel Pintor, Mário Pinto: “The Extended Construction Enterprise", INESC Porto Internal Report 1999.

4. [GERAM]

"Generalised Enterprise Reference Architecture and Methodology", Version 1.5, 199709-27 IFIP - IFAC Task Force

5. [Pinto]

Mário Pinto: "Workflow Management System in Processes Co-ordination in the Extended Construction Enterprise " MSc Thesis 2000

6. [WfMC]

Lawrence, Peter: "Workflow Handbook 1997"; John Wiley \& Sons Lda.

7. [Vernadat]

Francois B. Vernadat: "Enterprise Modelling and Integration, Principles and Applications", Chapman \& Hall

8. [V. Rembold]

V. Rembold, B.O. Nnaji, A. Storr: Computer Integrated Manufacturing and Engineering, Addison-Wesley 